\title{
Belief in a Just World and Judgment in Moral Dilemmas
}

\author{
Traipop Chaturapanich ${ }^{1} \&$ Apitchaya Chaiwutikornwanich ${ }^{1}$ \\ ${ }^{1}$ Faculty of Psychology, Chulalongkorn University, Bangkok, Thailand \\ Correspondence: Traipop Chaturapanich, Faculty of Psychology, Chulalongkorn University 7th Fl. \\ Borommaratchachonnanisrisattapat Bldg., Rama 1 Rd. Pathumwan, Bangkok, 10330, Thailand. E-mail: \\ traipop333@gmail.com
}

\author{
Received: August 2, 2015 Accepted: September 23, 2013 Online Published: September 28, 2015 \\ doi:10.5539/ass.v11n23p178 URL: http://dx.doi.org/10.5539/ass.v11n23p178
}

\begin{abstract}
This paper addresses the influence of belief in a just world on moral judgment using moral dilemmas by observing the interactions with the following independent variables: 1) dual-process cognitions (automatic or deliberate), 2) the protagonist's fate (bad, good, or absent), and 3) the type of dilemma (life-threatening or not). The results found no effects of belief in a just world on moral judgments. But an interaction between the protagonist's fate and the dilemma type emerged as significant. In Study 1, the protagonist was identified as a victim, the participants accepted moral violations against the bad fate victim to a greater extent in the life-threatening situation (turning the car to crash into one man in order to save five men) than in the non-life-threatening situation (choosing an employee for dismissal to save the company's financial status). In Study 2, the protagonist was specified as an offender. The participants accepted the violations against the good fate offender to a greater extent in the non-life-threatening than in the life-threatening situation. Meanwhile, the participants in the control groups (for whom the protagonist was not affected by fate) of both studies exhibited greater acceptance of moral violations in the non-life-threatening than the life-threatening situations.
\end{abstract}

Keywords: just world, moral dilemma, moral judgment, fate, protagonist

\section{Introduction}

Sometimes in daily life, people may experience certain moral situations that are difficult to identify objectively as being right or wrong, such as immoral situations that are supported by particular reasons, e.g., a woman competes in a topless show on Thai TV to financially assist her father, who is seriously ill, or a poor woman is arrested for selling a few copyrighted CDs taken from waste piles, although her actions seemed to be the only way she could be able to raise her children. How do you think about these events? Do you sympathise with the woman or not? The question is whether choosing one choice can affect others because the alternative judgments in these situations are between following the rules or ignoring the principle and thinking of utility. In the two cases above, following the rule would entail criticising the topless woman for violating the moral norm and obeying the law by agreeing with arresting the poor woman. Considering utility, however, would entail sympathising with and assisting the topless woman and disagreeing with arresting the poor woman. As a result of the differing points of view, some people may perceive these situations as unjust, leading to numerous arguments from different perspectives that affect the involved persons more or less positively or negatively. Additionally, separate from the moral judgment, the justice motive is also an important factor in individuals' moral judgments (Lerner, 1977; Montada, 1998). The reality of unjust situations is that some of them cannot be changed, but a mental mechanism takes effect: believing in a just world helps people cope with the stress of perceiving unjust situations by assuming that everyone gets what they deserve, particularly penalties-legal, social, or otherwise-about which people might say: "You deserve it" or "What goes around comes around". As such, people who are judged as bad are perceived as people who must and will be punished sooner or later (Lerner \& Miller, 1978). This belief can be observed in many societies and cultures (Furnham, 2003; Hunt, 2000), but there are no studies regarding how this belief affects judgment, especially in morality-based situations such as the ones above. This gap in the literature is the origin of this research, and, moreover, this study includes related additional variables from the literature review in order to extend the knowledge. The additional variables are as follows: 


\subsection{Moral Judgment}

First, the dependent variable was clarified: Moral judgment is an evaluation or opinion formed as to whether some action or inaction that an individual applies in discriminating between right and wrong. It tied to moral development that originated from cognition processes related to three types of justice reasoning, i.e., equality, equity and reciprocity (Kohlberg, Levine, \& Hewer, 1983). In early development, an individual views justice as direct reciprocity, but later, fairness is approved by not referring to any social norm. Persons might justify their own actions or the actions of others and then compare them with their long-held moral standards, which also involves appraisals (Kuhn, 1989; Nisbett \& Ross, 1980). These appraisals are in the form of moral reasoning that can take place unconsciously and be contaminated by bias or errors (Ditto \& Liu, 2012; Kestner, 2009).

Additionally, moral judgment can be divided into two ways: the first is deontological, which is based on an ideal principle without the need for contextual factual information that justifies the action (e.g., obeying the law by agreeing with arresting the poor woman who selling copyrighted CDs taken from a garbage pail); the second is utilitarian, which is considered to be the result of an action that will be justified as having led to benefits (e.g., sympathising the poor woman who made illegal sale of CDs because fostering her children) (Broeders, van den Bos, Müller, \& Ham, 2011).

Haidt (2001) created the social intuitionist model, which describes moral judgment as occurring quickly and intuitively. If asked, an individual will gradually find a moral reason for what happened after the fact. Moral intuition is considered to be a type of cognition, but it is not the same as reasoning, which can immediately take the form of either approval or disapproval through feelings and emotions. Moral intuition comes from both natural selection and cultural forces (Greene \& Haidt, 2002).

\subsection{Moral Dilemma}

A moral dilemma is a situation involving a conflict between two alternative choices, both of which interest us. It has a similar structure to daily life events that people may be confronted with because there is always a conflict in moral dilemmas between the deontological (follow the rule) and the utilitarian (what is the best outcome) that cannot be avoided. The moral violation implied by each chosen path often causes cognitive dissonance (Brehm, 1956). Moral dilemmas were first described by Kohlberg (1964), who studied people's moral reasoning using a scenario called the "Heinz dilemma".

Subsequently, Foot (1978) created the "Trolley Problem", which is a well-known and commonly used scenario about "an uncontrollable trolley running along the rail that five workmen are working on. Everyone is going to die if there is a crash. However, the driver can press the button to control the trolley to change to the other direction, where only one workman is working. Certainly, that workman would be killed. The question is, should the driver allow the trolley to run along the rail, crash, and kill the five workmen, or should he change direction and crash into and kill only one workman?" Accepting the violation on a workman by pressing the button to change direction indicates to the utilitarian judgment, whereas, denying this action signifies deontological.

Later moral dilemmas were extended and developed in a variety of plot stories. Greene, Sommerville, Nystrom, Darley and Cohen (2001) developed the original "Footbridge Dilemma", which involved using a remote control to let a stranger fall through a hole in a bridge. Suter and Hertwig (2011) created and applied moral dilemmas in situations that were either related or unrelated to potential life-threatening harm, e.g., the Lost Wallet Dilemma.

Whatever the moral dilemma, they take the same structure as the story structures that are used in experimental contexts. First is the preliminary story, which should identify the protagonist, and then the story develops to the dilemma itself, in which the reader learns about the two possible choices of action or inaction towards the minority (one person in the case of the Trolley Dilemma) and the majority (five persons) of the people in the situation. Each choice will always confer an advantage to one side, but it will also violate the other side. Finally, the situation comes to the moral judgment question about which choice should be approved (violate one person to help more people or not) (Christensen \& Gomila, 2012).

\subsection{Belief in a Just World (BJW)}

Belief in a just world is a concept from Lerner that arose in one study when he found that students believed that their friends, who were in fact rewarded randomly, were the harder workers, even though they knew about their friends' work patterns (Lerner, 1965) and in another experiment (Lerner \& Simmons, 1966) that assigned the female participants to watch a video about a student who received a punishment of an electric shock because the student made a mistake. In one condition, the experimenter told the participants that the electric shock had to be continued without any compensation. The result revealed that the participants came to devaluate the students by evaluating their attractiveness as lower than those of the students in the other condition. This phenomenon is 
known as "victim derogation" (Lerner \& Miller, 1978), and it occurs when one believes that the victim or the bad fate person deserved unreasonable suffering.

BJW is the belief that this world has stable rules under which good people receive good things as rewards and bad people receive bad things as punishment. That is, no matter what happens to a person, whether good or bad, he or she deserved it, perhaps because of past good or bad actions that are reflected in present-day consequences. This belief is considered to be a common justice motive of human beings (Montada, 1998), and most people hold this belief to some degree (Lerner, 1980). Some parts of BJW are influenced by social learning, which can be observed in fairy tales that typically end with the good protagonists' attaining good endings while the bad persons or behaviours are punished. Additionally, power and religion are important cultural factors in BJW, just as dignity and popularity are typically associated with goodness (Rubin \& Peplau, 1975).

In the view of social psychologists, BJW is described as a cognitive bias (Olson, Dunham, Dweck, Spelke, \& Banaji, 2008) and is used to relieve the stress of daily life's oppression from viewing injustice in society (Kestner, 2009). As an early study, Rubin and Peplau (1973) found a positive correlation between BJW and insults towards blacks $(r=.21)$ and females $(r=.31)$. The persons who believed in a just world legitimised the events by perceiving unjust events as occurrences that happened to those who deserved them (Maes \& Schmitt, 1999). The exceptions occurred when the persons did not hold a BJW stance or doubted other aspects of the context, such that BJW was replaced with moral reasoning (Oppenheimer, 2005). Montada (1998) indicated that blaming occurs when a victim's innocence threatens a person who follows the BJW approach. If a person believes that a victim did not deserve the bad fate, blaming is more possible, particularly if the victim's distress cannot be compensated for (Hafer, 2000; Lerner, 2003).

Moreover, not only bad fate persons but also in good fate, high BJW persons have more positive illusory evaluations of individuals' positive characteristics. One study found that the believers who were rating photos rated the attractive males in the photos as more socially desirable $(M=90.94)$ than did the unbelievers $(M=$ $75.50)$ and as more desirable than the unattractive males in the photos $(M=72.44)$. Additionally, BJW persons estimated that attractive persons would have life outcomes that were better than those of unattractive ones (Dion \& Dion, 1987).

In the previous research, we found no studies about the direct influence of belief in a just world on moral judgment within moral dilemmas in the field of social psychology. However, some studies offer clues that could link to this study. Wendorf, Alexander and Firestone (2002) found a correlation between some moral structures and distributive justice that included equity (which was quite similar to the BJW concept), and in the context of organisations, Ahmad, Ansari and Aafaqi (2005) suggested that high BJW managers exhibited utilitarian judgment in honesty-related dilemmas more often than in control-related dilemmas, and this phenomenon was not observed in low BJW persons.

\subsection{Dual-process Cognitions (DPC)}

One remaining question is whether the kind of moral judgment or the effect of belief in a just world are also related to the thinking process that comes from intuition versus reason. Suter and Hertwig (2011) studied moral dilemmas and divided the conditions by time in a manner that was controlled by a computer: one condition was up to 8 seconds, to force participants to think from intuition, and the other allowed for up to 3 minutes to let the participants reason through the situations. The results revealed that in the high-conflict dilemma (choosing to harm others directly by their own hands), the participants more often chose not to harm in the 8 s condition compared with the $3 \mathrm{~m}$ condition, when they had more time to think. However, the judgments were not different in the low-conflict dilemma condition. Although the control of the timing was changed in Study 2 from a computer to an allocation by the experimenter, the study results were concordant.

Similar to a belief in a just world, the feeling of deservingness must occur via intuition, particularly in low-impact situations (situations that do not directly harm others), whereas high-impact situations (those that directly harm others) motivate people to think of norms and relevant information with reasons. However, people might respond in a manner more motivated by intuition than by reason if they are asked to express their true feelings (Lerner, 2003).

Furthermore, there is an additional conclusion that people's moral judgments tend to differ-between deontological or utilitarian-depending on the variables mentioned above, as follows:

1. The conditions do not allow for much thinking (in which case, judgment is most influenced by intuition) or they have great impact on emotions. Most people have settled on a more deontological (do not accept harming one life for the survival of many) than utilitarian (considering the best solution to be harming one life to help 
many) approach to moral dilemmas (Cushman, Young, \& Hauser, 2006; Greene et al., 2001; Moore, Stevens, \& Conway, 2011; Petrinovich, O'Neill, \& Jorgensen, 1993; Suter \& Hertwig, 2011).

2. In situations that indirectly hurt others or that has no bearing on harming others, people will tend toward utilitarianism whether the judgment comes from intuition or reasoning (Greene et al., 2009; Suter \& Hertwig, 2011).

It can be seen that thinking styles and the different types of situations can affect moral judgment. Therefore, what should happen if the protagonist in the dilemma has a bad or good fate that could affect the person who believes in a just world? Past research has found that persons who approach life with BJW may consider that the bad fate person deserved his or her bad outcome because (s)he likely did something bad in the past. It has been found that high BJW people evaluated bad fate people as lower than average in multiple aspects (Cozzarelli, Wilkinson, \& Tagler, 2001; Dion \& Dion, 1987; Lerner \& Simmons, 1966; Maes \& Schmitt, 1999; Montada, 1998; Rubin \& Peplau, 1973). They tend to derogate the victim, such as prejudice against the poor and/or unemployed, the elderly, prisoners, the severely ill, patients with neuroses, immigrants, etc. (Begue \& Bastounis, 2003; Bizer, Hart, \& Jekogian, 2012; Kestner, 2009). Similarly, BJW people tend to believe that good fate persons deserve their good outcomes because of previous good actions. It was found that high BJW people felt that the lottery winner in the scenario was more deserving if it was a good person or someone who had done good things before (Callan, Ellard, \& Nicol, 2006).

Therefore, if a victim (or an offender) can be identified as a bad or good fate person in a moral dilemma, the following may result:

3. A BJW person may perceive a bad fate victim to be a bad person who is more deserving of being violated; the moral violation of the victim in the moral dilemma tends to be more accepted based on the phenomenon of victim derogation. Similarly, a good fate victim, however, may be perceived by the BJW person as a good person, and any moral violation against this person tends to be less accepted.

The next question is how persons with BJW change their views when the victim is now the offender. In real life, people are known to argue about violation situations such as when a man is killed in a car crash and people are asked to judge whether the driver did something spectacular or is just an ordinary man. We would expect the following:

4. A BJW person may perceive the bad fate offender to be a bad person and will therefore be less accepting when that offender violates one life, even if he atones for it by helping many others. Similarly, the BJW person may perceive a good fate offender to be a good person and be more accepting of the moral violation that occurred.

We suggest that people with BJW who meet bad or good fate persons assess those persons' deservingness and link it to the persons' characteristics, causing the BJW person to derogate a person who was judged as bad or admire a person who was judged as good. As such, how will the BJW person react when encountering bad or good fate victims (study 1), and bad or good fate offenders (study 2 ) in a moral dilemma?

We expected that belief in a just world would influence moral judgment because this belief may persist into adulthood to differing degrees (Callan et al., 2006; Piaget, 1965) as a mental mechanism to cope with the frustration from perceiving unfair events (Strelan \& Covic, 2006). That is, we suggest that BJW depends less on moral development and is more influenced by the motivation to maintain a sense of justice (the justice motive).

In other words, when the protagonist (the victim or the offender) in a moral dilemma has bad or good fate, the BJW person may feel threatened. Thus, individuals with different levels of BJW should have different moral judgments (accepting level in the violations against one man for helping five men) based on their underlying justice motives.

In this study, we modified the traditional moral dilemma to threaten the feeling of justice by manipulating the protagonist to have different fates, either bad or good (or absent in the control group), that exist in real people's lives. Then, we measured people's moral judgments, treating belief in a just world as a causal variable.

In addition to the protagonists' fates, the effect of BJW may interact with the associated variables that we mentioned above, i.e., 1.) type of moral dilemma (because harming another inevitably affects one's emotions and should result in a different judgment than that which would be held based on an action that caused trouble but did not harm anyone's life) and 2.) DPC (thoughts that come from either intuition or reasoning). These variables would cause moral judgments to differ as well (Greene et al., 2001; Suter \& Hertwig, 2011), and as such, BJW may interact with these variables and affect moral judgment in two ways, i.e., being more (utilitarian) or less (deontological). Accepting of moral violations. 


\section{Present Study}

We created moral dilemmas in which the main story was about an offender who made a moral violation against one victim in order to help five others to survive. We also assigned bad or good fates to the character who was the protagonist; the fates were assigned to the victim (the protagonist in Study 1) and to the offender (the protagonist in Study 2). The moral dilemmas were also divided into two types, a life-threatening situation (the action in the situation would harm another's life) and a non-life-threatening situation (the action would not harm anyone's life, but would cause disruption).

First, we considered confounding variables that might have needed to be controlled for in order to more clearly demonstrate the effect of BJW on moral judgment: 1. Moral dilemmas can reduce the impact of the situation on a participant's emotions, and thereby conceal the influence of BJW, because the moral violation is supported by reason (harm one to help the majority) and does not originate with intention; 2 . The protagonists' bad fates are primarily considered to result from prolonged retribution that cannot be compensated for; 3 . All characters are male and are not identified by race or age in order to control for compassion or prejudice; and 4 . The perspective of the participants who read the situation was that of an observer to avoid any self-serving bias regarding the judgment. Moreover, the DPC were manipulated by using an online timer to either hasten participants to think quickly or allow them to think slowly.

The moral judgments were evaluated by the acceptance of the harm-doer's committing a moral violation by harming one person to save five others (Greene et al., 2009); we used the following questions: Was it wrong or right? (Nichols \& Mallon, 2006; Usoof-Thowfeek, Janoff-Bulman, \& Tavernini, 2011) Was it appropriate or inappropriate? (Greene, Nystrom, Engell, Darley, \& Cohen, 2004) Should it have been blamed or praised? The average scores indicated the moral judgments (higher scores indicated more accepting of the moral violation).

\subsection{Hypothesis}

We expected to observe interactions between the independent variables (i.e., BJW, the protagonists' fates, dilemma type and DPC) effect on moral judgment.

In Study 1, we looked for a strong positive influence of BJW on moral judgment in the bad fate protagonist condition because when a bad fate victim is harmed, high BJW persons agree more strongly with the moral violation (the action of harming one person to save five others) than do low BJW persons owing to the victim derogation mechanism. However, regarding the good fate protagonist condition, BJW might have a weaker positive influence on the judgment than it had in the bad fate condition because the high BJW persons might perceive the good fate victim as a more desirable person who did not deserve this harm. Moreover, these phenomena should show their strongest influence in the non-life-threatening situation, which has less impact on emotions, together with the automatic cognition (thinking quickly), which judgment should stem from intuition.

In contrast, in Study 2, we expected that BJW might have a strong positive influence on moral judgment in the good fate protagonist condition because when the good fate offender harms one person to help many others, high BJW persons agree more strongly with the moral violation than do low BJW persons because the high BJW persons evaluate the offender more positively while regarding the bad fate offender as undesirable; in this scenario, the bad fate offender's violations might be less accepted. These factors should also have the most influence in the non-life-threatening situation, together with automatic cognition.

\section{Materials}

The BJW scale of Rubin and Peplau (Lipkus, 1991; Rubin \& Peplau, 1975) was selected because its contents reflect the belief in multiple forms, such as general meaning and the deservingness of events (including reverse items), and it is related to various contexts, i.e., family life, health, education, politics, and law. This scale can predict participants' reactions to victims better than the scale of Lipkus (1991) (Braman \& Lambert, 2001). Some contents were modified for concordance with Thai contexts, including the inclusion of additional items and the expansion of the scale to seven points $(1=$ absolutely not agree to $7=$ absolutely agree). Finally, the scale passed the corrected item-total correlation (CITC) with the inclusion of 22 items with an alpha of .810 and a tested validity using the 'known group' procedure, which revealed significance in the mean differences between the higher BJW persons (judges, prosecutors and lawyers) and the lower BJW persons (private-sector employees), $t(68)=3.56, p<.01$.

The moral dilemmas were created based on the conclusions of Christensen and Gomila (2012). In the initial, development stage, we created three situations for each dilemma type with the following characters: the offender, a person who encountered two alternatives and chose to violate a victim in exchange for five survivors (i.e., a life-threatening dilemma that included the 'driving situation' adapted from the Trolley Dilemma by Foot (1978); 
the 'yacht situation', adapted from lifeboat situation (Zimmer, 2004); and the 'graft situation', which was based on the doctor's sick patients from an article by Hopkins (2011). We created brand-new non-life-threatening dilemmas: the 'dismissal situation', the 'detective situation' and the 'contest situation'.

We tested these moral dilemmas with ninety-seven participants in order to select only one situation of each type for use in the experiment; we matched the results based on the following criteria: 1. the scenario had similar frequencies of agreement and disagreement in terms of moral violation in order to avoid bias related to the story in the situation; 2. the most participants could clearly identify the offender and the victim and knew that they only had two choices; and 3 . the most participants greatly expected that the story was true.

Finally, the chosen life-threatening dilemma was the following driving situation:

"Mr. Ton is driving a car along a road to go home as usual at an approximate speed of 80 kilometres per hour. In front of him, he sees five workmen mending the road, delivering equipment, and crossing the road. Therefore, Mr. Ton brakes to slow his car, but the brake system has a problem, and he cannot stop the car. The car is speeding to crash and cause the unavoidable deaths of all five workmen. The only thing that he can do is turn his car onto the sidewalk, where a man is walking. The car has to speed toward that man and kill him. Ultimately, Mr. Ton decides to let his car run onto the sidewalk and crash into that man, causing his death."

The non-life-threatening dilemma was the following dismissal situation:

"A company is encountering financial problems and has to close soon. Some employees in each department need to be fired for the company's survival. Mr. Jom is the chief of the sub-department of the marketing division. He has six subordinates, and he was assigned by the manager to fire one employee in his department, but his employees have all made contributions and exhibited good habits. Therefore, Mr. Jom decided by himself. Ultimately, he chose a male employee for dismissal."

The two moral dilemmas above were used for the control group (the protagonist has no fate). In the bad or good fate conditions, we assigned the fates to the protagonists in both types of dilemma. The fates in the development stage were based on literature reviews and daily news that was classified to conform with the BJW concept in terms of health (e.g., cancer, AIDS, insanity, disability, long life, being an athlete, being completely cured from cancer, etc.), social status (e.g., being a beggar, homeless, thief, addicted to drugs, company owner, millionaire, famous movie star, etc.), and fortune (e.g., being raped, being hurt, bankrupt, winning big in the lottery, surviving an accident, etc.).

The same ninety-seven participants (one was excluded for missing data) selected the first three bad and good fates based on their opinions, and the frequencies were then calculated. The three most-selected fates of each type were used for the experiment (picking three fates rather than one for preventing from bias). Because some fates were inappropriate in the context of the situation (for example, being raped was the second selection but was not suitable for the protagonist's gender, and being blind was not suitable for an offender who was a driver), we selected the next most popular fates. Consequently, the three bad fates were a handicapped arm or leg, being cheated and becoming bankrupt, and suffering from cancer, and the three good fates were surviving an accident, being completely cured of cancer, and winning a large lottery.

One example of how we used fate in the moral dilemmas (e.g., using a bad fate protagonist in the life-threatening situation in Study 1) is the following: “... The only thing that he can do is to turn his car onto the sidewalk, where a man who is ill with cancer is walking. The car has to speed toward that man and kill him. Ultimately, Mr. Ton decides to let his car run onto the sidewalk and crash into that ill man, causing his death."

Another is using a good fate protagonist in the non-life-threatening dilemma in Study 2: “...Some employees in each department need to be fired for the company's survival. Mr. Jom, who survived a plane crash, is the chief of the sub-department of the marketing division..."

The scale of moral judgment consisted of five items that were similar to a semantic differential scale that comprised opposite adjectives, i.e., wrong or right, blameworthy or praiseworthy, forbidden or permissible, unacceptable or acceptable, and inappropriate or appropriate and that were scored on a seven-point Likert scale ( 1 to 7 rather than -3 to +3$)$. The average scores indicated the moral judgments; scores above the median (4 points) indicated tendencies toward utilitarianism (more accepting of the moral violation), whereas lower scores indicated a deontological (less accepting of the moral violation) stance. The scale was tested with fifty-six participants, and all items passed the CITC test with alphas of .841 and .852 when tested in the life-threatening and non-life-threatening situations, respectively.

Finally, the moral dilemmas and all scales were arranged on an online questionnaire website with a countdown timer for manipulating DPC. Seventy-five participants were separated into two groups to read two types of 
situations and respond. Based on the results of this development stage, we determined that the appropriate response time in the automatic condition was no longer than 9 seconds per one moral judgment item. In the deliberation condition, the time was no shorter than 1.30 minutes per all five moral judgment items. The front screen of each situation was not determined in terms of time because the participants were required to read the situations until they understood without time pressure, and, according to the data, there were no differences in situation reading times between groups.

\section{Study 1}

In the first study, we expected to observe effects of BJW on moral judgment in terms of interactions with DPC, fates, and dilemma types when the fates were those of the protagonist and the protagonist was also the victim.

\subsection{Participants}

The sample size was determined with G*Power 3 (Faul, Erdfelder, Lang, \& Buchner, 2007), and the medium effect sizes and numerator $\mathrm{df}$ were calculated. College students from three universities in Bangkok-Chulalongkorn University, King Mongkut's University of Technology North Bangkok, and Srinakharinwirot University-who were in general education courses were then recruited by the assistants. The sampling procedures were approved by the Ethics Review Committee for Research Involving Human Research Subjects, Health Science Group, Chulalongkorn University. Approximately 3\% of the extreme and incomplete data were excluded. Finally, 360 participants from 19 faculties including 180 females ranging in age from 18 to 25 were deemed valid cases.

\subsection{Method}

As with the online questionnaires, the participants began by providing personal information and then read and responded to a fake scenario adapted from the 'Heinz dilemma' (Kohlberg, 1964) that was inserted for readiness preparation. Next, the participants were randomly assigned by the website system to one of twelve conditions as between-subjects design that were classified into 2 cognitions (automatic or deliberate) x 3 protagonist fates (bad, good or absent) x 2 dilemma types (life-threatening or non-life-threatening). Each condition comprised thirty participants in proportions in terms of gender. Altogether there were three scenarios of the bad fate and three scenarios of the good fate, thirty participants in these conditions were randomly experienced one of three bad or one of three good fates, ten participants per scenario.

When the participants had finished reading the situation and clicked the 'next' button to enter the moral judgment questions screen, in the automatic cognitive condition, the items randomly appeared on the screen one question at a time (in order to participants focus and response in each item immediately), with a countdown timer of 9 seconds and red text messages that stated, "Please answer the question before the time is over!". The participants were required to respond and then to click the button for the next page. If the time ended, the screen automatically changed to the next question. In the deliberative cognitive condition, all five items appeared together at the same time with a countdown timer of 90 seconds (1.30 minutes), and blue text messages that stated "You have 1.30 minutes; please think carefully before answering the question" were shown. The participants could not continue to the next screen until the time ended. Afterwards, they responded to the BJW scale.

\subsection{Results}

The mean moral judgment was $3.86(S D=1.32)$, and the mean BJW was $4.02(S D=0.47)$. There were no differences in the homogeneity of variance or the homoscedasticity. Next, variables were analysed with Pearson and polyserial correlations. BJW and DPC were found to exhibit no significant correlation with moral judgment, $r(358)=-.002, n s$ and, $r(358)=-.006, n s$, respectively; however, the dilemma types and the protagonists' fates were significantly correlated with moral judgment, $r(358)=.045, p<.05$ and, $r(358)=-.069, p<.05$, respectively.

As a result, the essential analysis, a three-way ANCOVA-2 (cognitions) x 3 (protagonist's fate) x 2 (dilemma types)-was conducted with BJW as a covariate. The BJW scores were improved by a grand mean centring to reduce the collinearity, and a test of the homogeneity of the regression slopes was employed to identify the interactions between the BJW scores and the categorical independent variables. The result was that there were no significant BJW effects $[F(1,336)=0.61, n s]$ or interactions between BJW and the category variables at any levels, but an interaction was found between the protagonist's fate and dilemma types. Therefore, BJW was removed, and all categorical variables were then reanalysed by three-way ANOVA. The result was that there were no significant main effects of DPC $[F(1,348)=0.008, n s]$ or dilemma type $[F(1,348)=0.491, n s]$. There 
were also no significant interactions between DPC, protagonist's fate and dilemma type $[F(2,348)=0.004, n s]$, DPC and dilemma type $[F(1,348)=0.094, n s]$ or DPC and protagonist's fate $[F(2,348)=0.285, n s]$.

However, the interaction between the protagonist's fate and dilemma type was strongly significant $[F(2,348)=$ $11.86, p<.001]$, and there was a main effect of protagonist's fate $[F(2,348)=7.15, p<.01]$. Thus, post-hoc analyses with Bonferroni tests were conducted on all possible pairwise comparisons. The following pairs of group conditions were found to be significantly different: 1.) bad fate protagonist in life-threatening $(M=3.88$, $S D=1.07)$ and non-life-threatening $(M=3.17, S D=1.42, p<.05)$ situations; 2 .) absent fate protagonist in life-threatening $(M=3.69, S D=1.28)$ and non-life threatening $(M=4.57, S D=1.23, p<.01)$ situations; 3 . $)$ bad fate protagonist $(M=3.17, S D=1.42)$ and good fate protagonist $(M=3.99, S D=1.24, p<.01)$ in non-life-threatening situations; and 4.) bad fate protagonist $(M=3.17, S D=1.42)$ and absent fate protagonist $(M$ $=4.57, S D=1.23, p<.001$ ) in non-life-threatening situations (Figure 1).

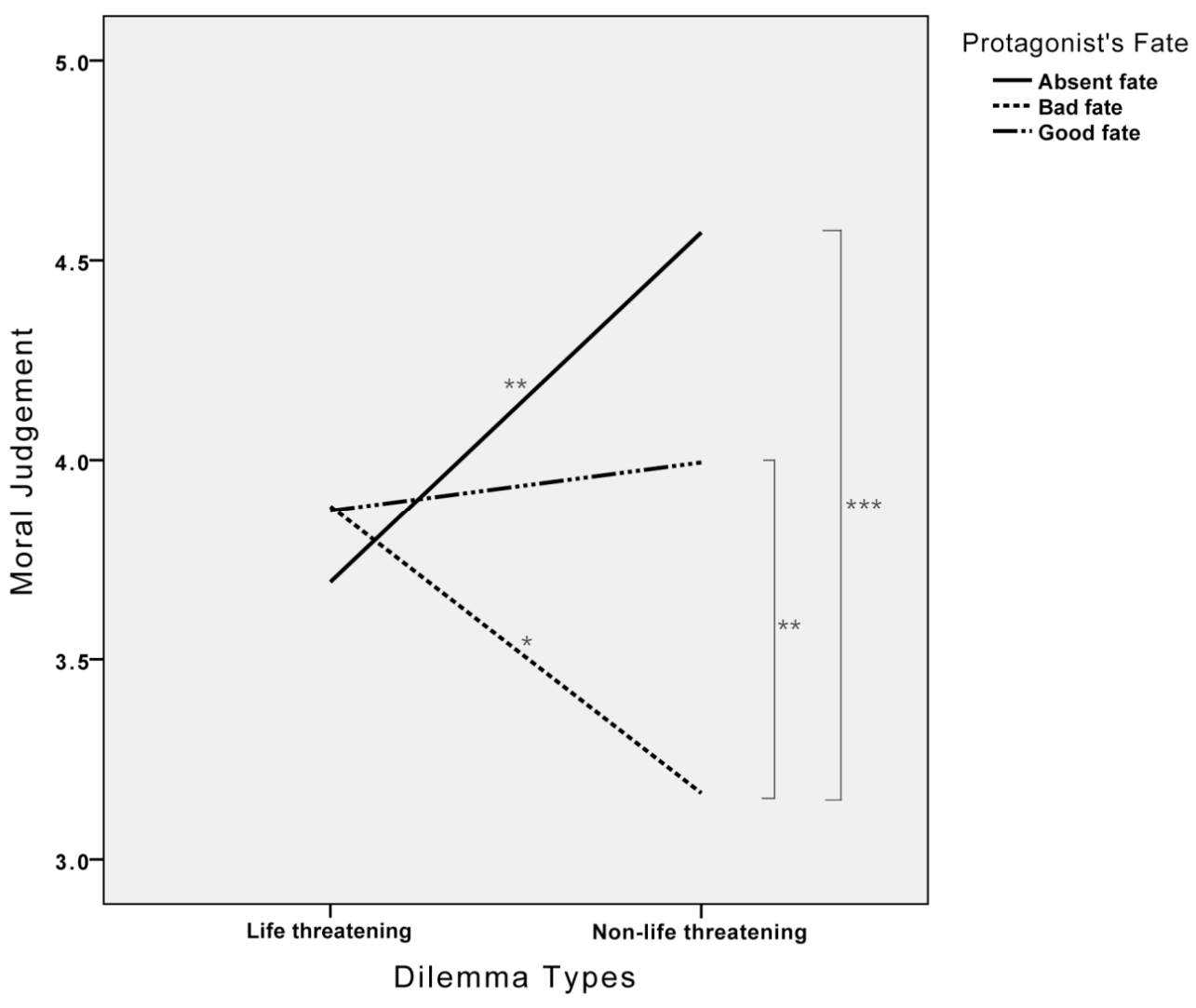

Figure 1. The moral judgment of victims with different fates between life-threatening and non-life-threatening situations (Study 1), ${ }^{*} p<.05,{ }^{* *} p<.01,{ }^{* * * *} p<.001$

\section{Study 2}

This study served as a replication of Study 1 except that the fates were moved to the offenders. We then tested the effect of BJW on moral judgment and the interactions with all categorical variables.

\subsection{Participants and Method}

Additional college students from the same three universities who attended general education classes were recruited by assistants according to the Ethics Review Committee's agreements. Approximately $2 \%$ of the extreme cases and incomplete data were excluded. Ultimately, 360 participants from 19 faculties, including 180 females ranging in age from 18 to 25 , were deemed to be valid cases. The researcher conducted the experiment in the same form as Study 1.

\subsection{Results}

The mean moral judgment was $3.92(S D=1.31)$. The mean BJW was $4.04(S D=0.50)$. Investigation of the homogeneity of variance revealed a significant difference in variance between the groups $[F(11,348)=3.02, p$ 
$<.01]$, although a data transformation was performed. Nevertheless, the violation of statistical assumptions could be relaxed because the sample sizes in each experimental condition were equal, and the homoscedasticity did not differ. A three-way ANCOVA with BJW as a covariate was conducted, and there were no significant BJW effects on moral judgment $[F(1,336)=0.13, n s]$ or any interactions with category variables at any level. There was, however, an interaction between protagonist's fate and dilemma types. Therefore, BJW was removed, and the category variables were reanalysed with a three-way ANOVA. The result was that the main effects of DPC $[F(1,348)=0.53, n s]$ and protagonist's fate $[F(2,348)=0.48, n s]$ were not significant. However, as with the first study, the interaction between the protagonist's fate and dilemma type was significant $[F(2,348)=3.72, p<.05]$, with a main effect of dilemma type $[F(1,348)=42.72, p<.001]$. Due to the assumption of homogeneity of variance was violated; post-hoc analyses with Dunnett's T3 tests were conducted on all possible pairwise comparisons. The following pairs of group conditions were found to be significantly different: 1.) Absent fate protagonist in life-threatening $(M=3.35, S D=1.34)$ and non-life-threatening $(M=4.63, S D=1.13, p<.001)$ situations; 2.) Good fate protagonist in life-threatening $(M=3.51, S D=1.38)$ and non-life-threatening $(M=4.38$, $S D=0.97, p<.01$ ) situations (Figure 2).

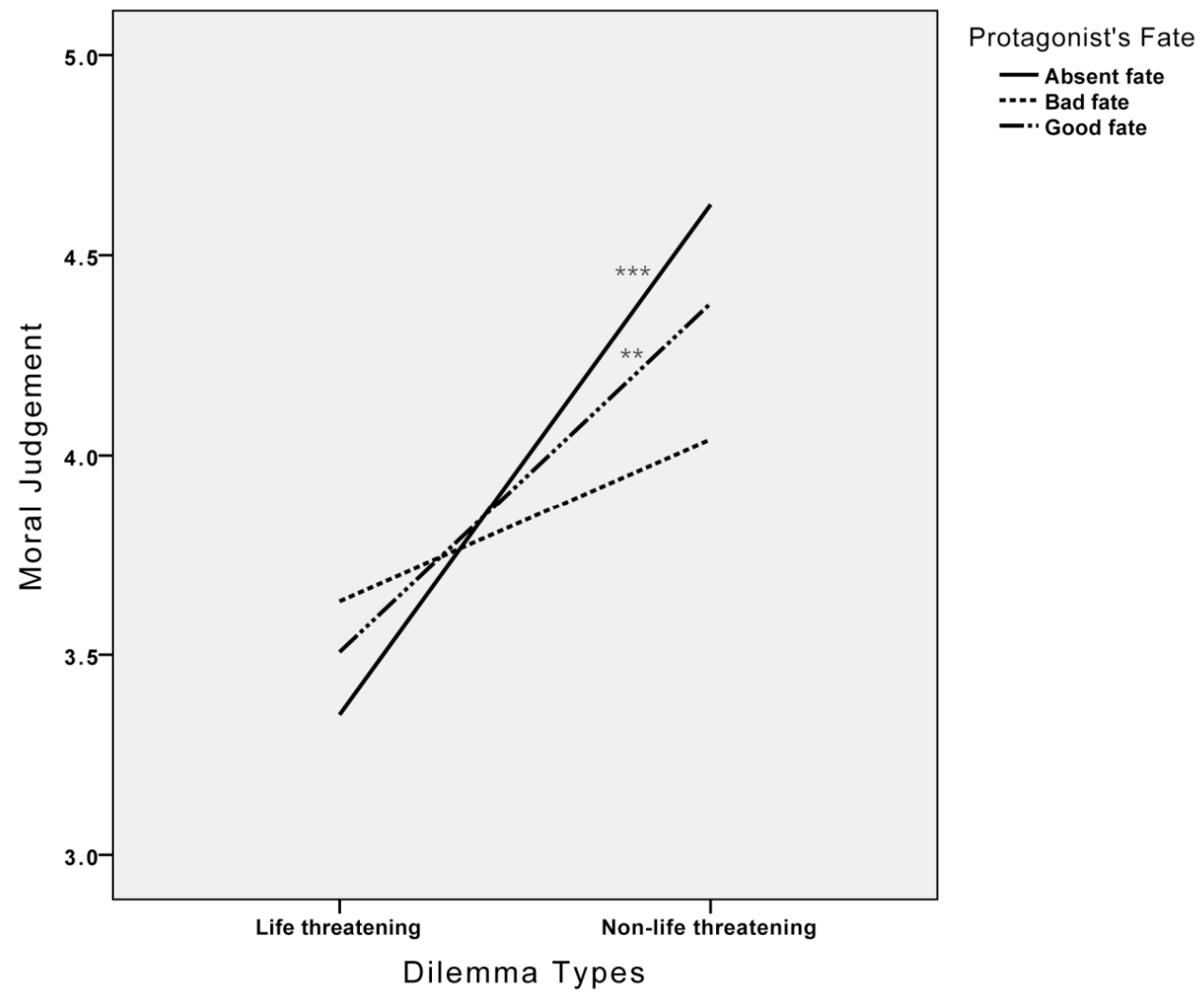

Figure 2. The moral judgment of the different offenders' fates between life-threatening and non-life-threatening situations (Study 2), $* * p<.01, * * * p<.001$

\section{General Discussion}

The effect of belief in a just world was not found, for a number of possible reasons. First, the influence of situations and questions, this study was conducted in terms of moral dilemmas, which are more complicated than normal forms of judgment because the participants were stimulated to focus more on dilemma scenarios. This might have caused moral judgments based on context consideration to outweigh the mechanism of BJW (Oppenheimer, 2005). Concordant as Lerner (2003) identified, BJW is clearly expressed in low emotional impact events on the heuristic forms of justice, but if context has high impact on emotion or induce individuals to engage with thoughtful response, it may be contaminated with another feelings such as compassion or comparison of equality, then the BJW mechanism might not take effect. Moreover, the question of moral judgment of this study focused on the action of moral violations rather than evaluations of the characteristics as has been done in previous BJW research, and thus it was more complex than the original BJW research. So it is 
possible that if the questions had been changed by asking on the deservingness of the protagonist, relationships between the variables might have been more clearly observed.

Second, BJW in individuals and their attitudes, the expression of BJW among participants of Study 1 and Study 2 was not quite different $[M=4.02, S D=0.47 ; M=4.04, S D=0.50$, respectively]. This finding might have been attributable to the maturity of moral development in accordance with the ages of the participants. The mechanisms of BJW might thus have been lower or hidden by more reasonable factors depends on growing age (or maybe the education level) of individuals (Oppenheimer, 2005; Piaget, 1999). Furthermore, we investigated the personal attitudes of some participants in study 1 by questionnaire, it revealed that most participants (30 out of 38 persons) were unsure and did not quite believe in the existence of justice in society, whereas the BJW scale that was used in this study consisted of items that were related to social context and could be perceived by individuals as injustice. Interestingly, most of the participants ( 35 of the 38 persons) believed in the law of karma, which has a quite similar construct to BJW. While BJW items indicated a short-term view of present life. But Karma is the long-term view of incidents, such as past existence and next lives, and it includes virtues and sins that are related to religion, particularly Buddhism, which influences Thai people. Therefore, it would be interesting to further study the role of beliefs in Karma on moral judgment.

Third, the techniques for measuring BJW, because of BJW might not be explicitly expressed all the time. We suggested that BJW would be expressed clearly in the specific forms of experiments to a greater extent than in the responses to a questionnaire. In an earlier study, BJW was already demonstrated in an experiment, such as an experiment of Lerner and Simmons (1966) that asked the participants for evaluating a student's attractiveness who've got an electric shocked without any compensation compared with the control group, thus victim devaluation expressed clearly from frustration that manipulated in an experiment. Whereas, questionnaires only measure explicit beliefs that can be contaminated with thoughts and reasoning (Hafer \& Begue, 2005; Lerner, 2003). Therefore, if a person does not feel frustrated enough, the effect of BJW might not occur (Lerner, 2003). This is considered to be a limitation of the present study.

In terms of cognitive processes, this study did not identify any differences of moral judgments between the conditions of dual-process cognitions. This lack of finding might be attributable to the influence of moral dilemmas that affect people's feelings. According to the additional interview, some of the respondents in deliberation condition made decisions immediately even when they had up to 1.30 minutes to consider. This is in accordance with Haidt (2001), which suggests that when people encounter moral dilemmas, even when they realise the facts of a situation, they will choose the answer based on their moral principles immediately from moral intuition. Although the persons were allowed to identify reasons, they could not infringe on their feelings of right and wrong, which is known as "moral dumbfoundedness".

However, the results from both studies revealed strongly significant effects of the interaction of the protagonists' fates and the dilemma types on moral judgment. From an overall point of view of both studies, the approval of moral violations related to the absent fate protagonist (control condition) in the non-life-threatening (choosing an employee for dismissal to save the company's financial status) situations was greater than that in the life-threatening (turning the car to crash into one man rather than five men in order to save their lives) situations. It revealed that disruption was more accepted than harming to life. In contrast, in the bad fate victim condition in Study 1, it was found that the moral violation on a bad fate victim in the life-threatening situation was more acceptable than in the non-life-threatening situation. It is in contrast with the absent fate victims (that mentioned above) and the good fate victims (that was not different among the situations). This finding can be interpreted in two ways. First, harming to a bad fate victim's life was more accepted than when the persecution did not harm life, it might have reflected the clue of "victim derogation" effect of the BJW mechanism (e.g., crashing on a bad fate victim cause his death is more accepted than dismissing a bad fate victim from a job); whereas, in the control condition, dismissing no fate victim from a job is more accepted than driving on no fate victim until he died). Second, the bad fate victim might have triggered more compassion in the participants in the non-life-threatening. Because of the dismissal, which would cause the victims to experience difficulty in life in the future? Consequently, the bad fate persons seemed to have double unfortunate destinies that might have made the respondents approve of the moral violations against him to a lesser degree than in the life- threatening, which he had been crashed that caused a bad fate victim ends suffering.

In Study 2, when fates were moved to the offender, the moral violations of good or absent fate offenders were more accepted in the non-life-threatening (dismissal) than life-threatening (car crash) situations. It might be because the role of moral intuition that harming life was less accepted than non-harming. Whereas, the approval of moral violation of bad fate offenders was not different among situations. In this case, bad fate offenders might 
have been devalued too, because of although the bad fate offenders just dismiss an employee, but his action might have seemed as badness and it did not differ at all from harming life.

In overall considerations, it is likely that the influence of protagonists' fate on moral judgment increased when it existed in the victims. Considering Study 1, the only significant main effect was that of the protagonist's fate on moral judgment. However, in Study 2 (when the fate was applied to the offenders), only a significant main effect of dilemma type was found. This might have been because of the role of the victim, who was unavoidably harmed. Thus, the feelings of justice might have been more triggered by the victim's fate than by that of the offender's fate, particularly in the cases of bad fate victims, which clearly affected moral judgment.

However, the discoveries of this study that moral judgments in life-threatening situation differed from non-life-threatening in a bad fate victim and in a good fate offender, help to elucidate how the forms of moral judgment in different moral dilemmas relate to protagonists' fates, which can serve as puzzles to be solved in additional studies of both BJW and moral dilemmas that can achieve the next explicit discovery.

\section{Acknowledgments}

This research was supported by CU.GRADUATE SCHOOL THESIS GRANT from Graduate School, Chulalongkorn University. The authors would like to express our gratitude to the contributors to and participants in this research.

Ethical approval all procedures performed in studies involving human participants were in accordance with the ethical standards of the Ethics Review Committee for Research Involving Human Research Subjects, Health Science Group, Chulalongkorn University, and with the 1964 Helsinki Declaration and its later amendments or comparable ethical standards.

\section{References}

Ahmad, N. H., Ansari, M. A., \& Aafaqi, R. (2005). Ethical reasoning: The impact of ethical dilemma, egoism and belief in just world. Asian Academy of Management Journal (pp. 81-101).

Begue, L., \& Bastounis, M. (2003). Two spheres of belief in justice: Extensive support for the bidimensional model of belief in a just world. Journal of Personality, 71, 435-463. http://dx.doi.org/10.1111/1467-6494. 7103007

Bizer, G. Y., Hart, J., \& Jekogian, A. M. (2012). Belief in a just world and social dominance orientation: Evidence for a meditational pathway predicting negative attitudes and discrimination against individuals with mental illness. Personality and Individual Differences, 52, 428-432. http://dx.doi.org/10.1016/j.paid. 2011.11.002

Braman, A. C., \& Lambert, A. J. (2001). Punishing Individuals for Their Infirmities: Effects of Personal Responsibility, Just-World Beliefs, and In-Group/Out-Group Status. Journal of Applied Social Psychology, 31, 1096-1109. http://dx.doi.org/10.1111/j.1559-1816.2001.tb02664.x

Brehm, J. W. (1956). Postdecision changes in the desirability of alternatives. Journal of Abnormal Psychology, 52, 384-389. http://dx.doi.org/10.1037/h0041006

Broeders, R., van den Bos, K., Müller, P. A., \& Ham, J. (2011). Should I save or should I not kill? How people solve moral dilemmas depends on which rule is most accessible. Journal of Experimental Social Psychology, 47, 923-934. http://dx.doi.org/10.1016/j.jesp.2011.03.018

Callan, M. J., Ellard, J. H., \& Nicol, J. E. (2006). The belief in a just world and immanent justice reasoning in adults. Personality and Social Psychology Bulletin, 32, 1646-1658. http://dx.doi.org/10.1177/01461672 06292236

Christensen, J. F., \& Gomila, A. (2012). Moral dilemmas in cognitive neuroscience of moral decision-making: A principled review. Neurosci \& Biobehavioral Reviews, 36, 1249-1264. http://dx.doi.org/10.1016/j.neubiorev. 2012.02.008

Cozzarelli, C., Wilkinson, A. V., \& Tagler, M. J. (2001). Attitudes toward the poor and attributions for poverty. Journal of Social Issues, 57, 207-227. http://dx.doi.org/10.1111/0022-4537.00209

Cushman, F., Young, L., \& Hauser, M. (2006). The role of conscious reasoning and intuition in moral judgment testing three principles of harm. Psychological science, 17, 1082-1089. http://dx.doi.org/10.1111/j.14679280.2006.01834.x

Dion, K. L., \& Dion, K. K. (1987). Belief in a just world and physical attractiveness stereotyping. Journal of Personality and Social Psychology, 52, 775-780. http://dx.doi.org/10.1037/0022-3514.52.4.775 
Ditto, P. H., \& Liu, B. (2012). Deontological dissonance and the consequentialist crutch. In M. M. P. R. Shaver (Ed.), The social psychology of morality: Exploring the causes of good and evil (pp. 51-70). Washington, DC, US: American Psychological Association. http://dx.doi.org/10.1037/13091-003

Faul, F., Erdfelder, E., Lang, A. G., \& Buchner, A. (2007). G*Power 3: A flexible statistical power analysis program for the social, behavioral, and biomedical sciences. Behavior Research Methods, 39, $175-191$. http://dx.doi.org/10.3758/BF03193146

Foot, P. (1978). Virtues and Vices and Other Essays in Moral Philosophy. University of California Press.

Furnham, A. (2003). Belief in a just world: research progress over the past decade. Personality and Individual Differences, 34, 795-817. http://dx.doi.org/10.1016/S0191-8869(02)00072-7

Greene, J. D., \& Haidt, J. (2002). How (and Where) Does Moral Judgment Work? Trends in Cognitive Sciences, 6, 517-523. http://dx.doi.org/10.1016/S1364-6613(02)02011-9

Greene, J. D., Cushman, F., Stewart, L., Lowenberg, K., Nystrom, L., \& Cohen, J. (2009). Pushing Moral Buttons: The Interaction between Personal Force and Intention in Moral Judgment. Cognition, 111, 364-371. http://dx.doi.org/10.1016/j.cognition.2009.02.001

Greene, J. D., Morelli, S. A., Lowenberg, K., Nystrom, L. E., \& Cohen, J. D. (2008). Cognitive Load Selectively Interferes with Utilitarian Moral Judgment. Cognition, 107, 1144-1154. http://dx.doi.org/10.1016/j. cognition.2007.11.004

Greene, J. D., Nystrom, L. E., Engell, A. D., Darley, J. M., \& Cohen, J. D. (2004). The neural bases of cognitive conflict and control in moral judgment. Neuron, 44, 389-400. http://dx.doi.org/10.1016/j.neuron.2004. 09.027

Greene, J. D., Sommerville, R. B., Nystrom, L. E., Darley, J. M., \& Cohen, J. D. (2001). An fMRI investigation of emotional engagement in moral judgment. Science, 293, 2105-2108. http://dx.doi.org/10.1126/science. 1062872

Hafer, C. L. (2000). Do innocent victims threaten the belief in a just world? Evidence from a modified Stroop task. Journal of Personality and Social Psychology, 79, 165-173. http://dx.doi.org/10.1037/0022-3514. 79.2.165

Hafer, C. L., \& Begue, L. (2005). Experimental research on just-world theory: Problems, developments, and future challenges. Psychological Bulletin, 131, 128-167. http://dx.doi.org/10.1037/0033-2909.131.1.128

Haidt, J. (2001). The emotional dog and its rational tail: A social intuitionist approach to moral judgment. Psychological Review, 108, 814-834. http://dx.doi.org/10.1037/0033-295X.108.4.814

Hopkins, D. (2011). 10 more moral dilemmas. Retrieved March 24, 2013, from http://listverse.com/2011/ 04/18/10-more-moral-dilemmas/

Hunt, M. O. (2000). Status, religion, and the" belief in a just world": Comparing African Americans, Latinos, and Whites. Social Science Quarterly, 325-343.

Kestner, J. M. (2009). Relating Color Blind Racial Attitudes, Social Dominance Orientation and Just World Beliefs. Retrieved April 9, 2013, from http://ecommons.luc.edu/luc_diss/235

Kohlberg, L. (1964). Development of moral character and moral ideology. In M. L. Hoffman, \& L. W. Hoffman (Eds.), Review of Child Development Research (pp. 381-431). New York, NY: Russell Sage Foundation.

Kohlberg, L., Levine, C. G., \& Hewer, A. (1983). Moral stages: A current formulation and a response to critics. New York, NY: Karger.

Kuhn, D. (1989). Children and adults as intuitive scientists. Psychological Review, 96, 674-689. http://dx.doi.org /10.1037/0033-295X.96.4.674

Lerner, M. (1980). The Belief in a Just World: A Fundamental Delusion. New York, NY: Springer. http://dx.doi. org/10.1007/978-1-4899-0448-5

Lerner, M. J. (1965). Evaluation of performance as a function of performer's reward and attractiveness. Journal of Personality and Social Psychology, 1, 355. http://dx.doi.org/10.1037/h0021806

Lerner, M. J. (1977). The justice motive: Some hypotheses as to its origins and forms. Journal of Personality, 45, 1-52. http://dx.doi.org/10.1111/j.1467-6494.1977.tb00591.x

Lerner, M. J. (2003). The justice motive: where social psychologists found it, how they lost it, and why they may 
not find it again. Personality and Social Psychology Review, 7, 389-399. http://dx.doi.org/10.1207/s 15327957pspr0704_10

Lerner, M. J., \& Miller, D. T. (1978). Just world research and the attribution process: Looking back and ahead. Psychological Bulletin, 85, 1030-1051. http://dx.doi.org/10.1037/0033-2909.85.5.1030

Lerner, M. J., \& Simmons, C. H. (1966). Observer's reaction to the "innocent victim": Compassion or rejection? Journal of Personality and Social Psychology, 4, 203-210. http://dx.doi.org/10.1037/h0023562

Lipkus, I. (1991). The construction and preliminary validation of a global belief in a just world scale and the exploratory analysis of the multidimensional belief in a just world scale. Personality and Individual Differences, 12, 1171-1178. http://dx.doi.org/10.1016/0191-8869(91)90081-L

Maes, J., \& Schmitt, M. (1999). More on Ultimate and Immanent Justice: Results from the Research Project "Justice as a Problem within Reunified Germany". Social Justice Research, 12, 65-78. http://dx.doi.org/10. 1023/A:1022039624976

Montada, L. (1998). Belief in a Just World: A Hybrid of Justice Motive and Self-Interest? In L. Montada, \& M. Lerner (Eds.), Responses to Victimizations and Belief in a Just World (pp. 217-246). Springer US. http://dx. doi.org/10.1007/978-1-4757-6418-5_12

Moore, A. B., Stevens, J., \& Conway, A. R. A. (2011). Individual differences in sensitivity to reward and punishment predict moral judgment. Personality and Individual Differences, 50, 621-625. http://dx.doi.org/ 10.1016/j.paid.2010.12.006

Nichols, S., \& Mallon, R. (2006). Moral dilemmas and moral rules. Cognition, 100, 530-542. http://dx.doi.org/ 10.1016/j.cognition.2005.07.005

Nisbett, R. E., \& Ross, L. (1980). Human Inference: Strategies and Shortcomings of Social Judgment. Prentice Hall Press.

Olson, K. R., Dunham, Y., Dweck, C. S., Spelke, E. S., \& Banaji, M. R. (2008). Judgments of the lucky across development and culture. Journal of personality and social psychology, 94, 757-776. http://dx.doi.org/10. 1037/0022-3514.94.5.757

Oppenheimer, L. (2005). Justice and the belief in a just world: A developmental perspective. Personality and Individual Differences, 38, 1793-1803. http://dx.doi.org/10.1016/j.paid.2004.11.007

Petrinovich, L., O'Neill, P., \& Jorgensen, M. (1993). An empirical study of moral intuitions: Toward an evolutionary ethics. Journal of personality and social psychology, 64, 467. http://dx.doi.org/10.1037/ 0022-3514.64.3.467

Piaget, J. (1965). The moral judgement of the child. Retrieved September 21, 2012, from http://archive. org/details/moraljudgmentoft005613mbp

Piaget, J. (1999). The Moral Judgment of the Child (reprint ed.). London: Routledge.

Rubin, Z., \& Peplau, A. (1973). Belief in a Just World and Reactions to Another's Lot: A Study of Participants in the National Draft Lottery1. Journal of Social Issues, 29, 73-93. http://dx.doi.org/10.1111/j.1540-4560. 1973.tb00104.x

Rubin, Z., \& Peplau, L. A. (1975). Who Believes in a Just World? Journal of Social Issues, 31, 65-89. http://dx. doi.org/10.1111/j.1540-4560.1975.tb00997.x

Strelan, P., \& Covic, T. (2006). A Review of Forgiveness Process Models and A Coping Framework to Guide Future Research. Journal of Social and Clinical Psychology, 25, 1059-1085. http://dx.doi.org/10.1521/jscp. 2006.25.10.1059

Suter, R. S., \& Hertwig, R. (2011). Time and moral judgment. Cognition, 119, 454-458. http://dx.doi.org/10. 1016/j.cognition.2011.01.018

Usoof-Thowfeek, R., Janoff-Bulman, R., \& Tavernini, J. (2011). Moral judgments and the role of social harm: Differences in automatic versus controlled processing. Journal of Experimental Social Psychology, 47, 1-6. http://dx.doi.org/10.1016/j.jesp.2010.07.016

Wendorf, C., Alexander, S., \& Firestone, I. (2002). Social Justice and Moral Reasoning: An Empirical Integration of Two Paradigms in Psychological Research. Social Justice Research, 15, 19-39. http://dx.doi. org/10.1023/A:1016093614893

Zimmer, C. (2004). Whose life would you save? Scientists say morality may be hardwired into our brains by 
evolution. Retrieved March 24, 2013, from http://discovermagazine.com/2004/apr/whose-life-wouldyou-save\#.UfKA5mQpaGo

\section{Copyrights}

Copyright for this article is retained by the author(s), with first publication rights granted to the journal.

This is an open-access article distributed under the terms and conditions of the Creative Commons Attribution license (http://creativecommons.org/licenses/by/3.0/). 